\title{
THE EFFECTS OF COMPETITION BETWEEN LARVAE OF STORED-PRODUCT MOTHS
}

\author{
${ }^{a}$ Department of Food, Environmental and Nutritional Sciences, Università degli Studi di Milano, Via Giovanni Celoria \\ 2, 20133 Milano, Italy. \\ Corresponding Author: Lidia Limonta; lidia.limonta@unimi.it
}

Locatelli D.P., Perez Garcia F.B., Limonta L. - The effects of competition between larvae of stored-product moths.

The competition between Idaea inquinata, Corcyra cephalonica, and Plodia interpunctella on an artificial diet was investigated. The experiments were carried out with eggs laid within 24 hours. In the first experiment, 20 eggs of one species were placed in a ventilated Petri dish with $10 \mathrm{~g}$ of diet and 20 eggs of one of the other species; in the second experiment, 20 eggs of one species and, after 7 days, 20 eggs of one of the other species were added. Experiments were carried out at $27 \pm 1{ }^{\circ} \mathrm{C}, 70 \pm 5 \%$ R.H. Each experiment was replicated 5 times and the number of days to complete the development and the number of emerged adults were recorded.

The number of $P$. interpunctella adults was not affected by the presence of $C$. cephalonica or I. inquinata. A delay in the development was only observed when $P$. interpunctella eggs were added to the medium already colonized by the other species. I. inquinata was the less competitive, as the number of adults decreased and the days to complete the cycle increased. The development of I. inquinata was prevented if P. interpunctella eggs were started at the same time. Larvae of this last species cannibalized eggs of the other two species.

I. inquinata was the least competitive due to the longer cycle, the lower mobility and the aggressiveness of the larvae of the other two species that cannibalized its eggs.

KeY-Words: Plodia interpunctella, Corcyra cephalonica, Idaea inquinata, Pyralidae, Geometridae.

\section{INTRODUCTION}

Plodia interpunctella (Hübner) and Corcyra cephalonica (Stainton) (Lepidoptera Pyralidae) are cosmopolitan and polyphagous species. $P$. interpunctella is less demanding in relation to temperatures, as the lower threshold of egg development is $15^{\circ} \mathrm{C}$ (ARBogast, 2007), and of pupae 13.8 ${ }^{\circ} \mathrm{C}$ (Johnson et al., 1995); larvae develop between 18 and 32 ${ }^{\circ} \mathrm{C}$, the optimum temperature is $28^{\circ} \mathrm{C}$ (SAvov, 1973). C. cephalonica requires higher temperatures, the optimum temperature is at $30-32{ }^{\circ} \mathrm{C}$, and the minimum temperature for reproduction is $20^{\circ} \mathrm{C}(\mathrm{Cox}$ et al., 1981). Idaea inquinata (Scopoli) (Lepidoptera Geometridae) is present all over Europe (SKINNER, 1984; NAVES, 1995; Flamigni \& BASTIA, 1998; GIANTI, 2001), develops on withered plants, hay and officinal plants (dried spices, herbs, and medicinal plants), but it can also consume cereal products (CANDURA, 1931a, b; TEMPEL, 1941; KRATOCHVIL, 1948; LOCATELLI et al., 2005). The trade in dried aromatic plants or vegetable packaging can favor the spread of this species in food plants and warehouses (NAVES, 1995). The optimum temperature, in a laboratory experiment on an artificial diet, is $26^{\circ} \mathrm{C}$ (LimONTA \& LocATELLI, 2013). Larvae are grey-green colored and adults are brown-yellow colored, so an infestation can be underestimated as this species is mimetic with the stored products.

These three species can develop on the same food products, and they could compete in warehouses. In the literature, papers deal with competition in natural habitats (DUDLEY et al., 1990; FABRE et al., 2004), or competition among phytophagous species (KARBAN, 1986; KAPLAN \& DenNo, 2007; DeVESCOVI et al., 2015; EATOUGH Jones et al., 2015; SIGMON, 2015; NTIRI et al., 2016; TUEHELER et al., 2016). Also, competition in stored-product insects has been studied (SMith, 1986; Giga \& CANHAO, 1993; Ollson et al.
2006; CUI et al., 2006; SAKKA \& ATHANASSIOU, 2018). In particular, Allotey \& KUMAR (1985) published results on competition between $C$. cephalonica and Cadra cautella (Walker) on cocoa beans, and C. cephalonica was the predominant species. In another paper $P$. interpunctella and C. cautella were reared on peanuts and the predominant species was $C$. cautella, as it can develop on rearing media with a high content in fat; however, with an artificial diet as a rearing medium, $P$. interpunctella was more competitive (Allotey \& Goswami, 2002).

In this paper, we consider the intraspecific competition between $P$. interpunctella and $C$. cephalonica, two widespread species, and I. inquinata that can develop on the same stored foods. Experiments were carried out on an artificial diet that contains a balanced amount of nutrients, as insects perform better on this than on natural diets (SHOONHOVEN et al., 2005).

The research aims to verify the hierarchy between species that can coexist on the same commodity in order to guide the choice and timing of control measures.

\section{MATERIALS AND METHODS}

\section{REARING}

Laboratory cultures of Plodia interpunctella (Hübner), Corcyra cephalonica (Stainton) and Idaea inquinata (Scopoli), maintained in a rearing room at $27 \pm 1{ }^{\circ} \mathrm{C}, 70 \pm 5 \%$ R.H. and L16:D8 photoperiod, were used for the experiments. The ingredients of the diet were $62 \mathrm{~g}$ bran, $8 \mathrm{~g}$ cornflour, $7 \mathrm{~g}$ wheat flour, $4 \mathrm{~g}$ wheat germ, $3 \mathrm{~g}$ dried yeast, $9 \mathrm{~g}$ glycerol, and $7 \mathrm{~g}$ honey (LimONTA \& LOCATELLI, 2013). Previous development tests proved this diet suitable for all the species studied. 
EXPERIMENTS

All the experiments were carried out with eggs laid within 24 hours. The eggs were obtained by placing newly emerged adults in a glass jar closed with tulle, turned upside down on a ventilated Petri dish with filter paper.

For each species, groups of 20 eggs were placed in a Petri dish with $5 \mathrm{~g}$ of diet, an amount sufficient for the development of the specimen.

Two sets of experiments were carried out in order to observe the competition among the species. In the first set of experiments, 20 eggs of one species were placed in a ventilated Petri dish with $10 \mathrm{~g}$ of diet and 20 eggs of one of the other species, namely 20 eggs of $P$. interpunctella and 20 eggs of $C$. cephalonica; 20 eggs of $P$. interpunctella and 20 eggs of I. inquinata; 20 eggs of $C$. cephalonica and 20 eggs of I. inquinata.

In the second set of experiments, 20 eggs of one species were placed in a ventilated Petri dish with $10 \mathrm{~g}$ of diet and, after 7 days, 20 eggs of one of the other species were added; namely 20 eggs of $P$. interpunctella and after 7 days 20 eggs of $C$. cephalonica, 20 eggs of $P$. interpunctella and after 7 days 20 eggs of I. inquinata, 20 eggs of C. cephalonica and after 7 days 20 eggs of $P$. interpunctella, 20 eggs of $C$. cephalonica and after 7 days 20 eggs of $I$. inquinata, 20 eggs of I. inquinata and after 7 days 20 eggs of $P$. interpunctella, 20 eggs of $I$. inquinata and after 7 days 20 eggs of C. cephalonica.

Each experiment was replicated 5 times and the number of days to complete the postembryonic development, in the tables indicated as development, and the number of adults emerged was recorded daily.

\section{STATISTICAL ANALYSIS}

Data, when normally distributed, were submitted to Oneway ANOVA and LSD test $(\alpha=0.05)$, otherwise, the Kruskal-Wallis test and Multiple comparisons of groups were performed (IBM SPSS Statistics 24).

\section{RESULTS}

The number of Plodia interpunctella, Corcyra cephalonica, and Idaea inquinata adults, developed from 20 eggs of each species reared alone on the artificial diet, was $18.8 \pm 0.58,17.4 \pm 0.75$, and $16.2 \pm 1.28$ respectively, and not significantly different (One-way ANOVA: $\mathrm{F}_{2,12}=2.292$ $\mathrm{P}=0.144)$. The development time of the three species was significantly different $\left(\chi^{2}=266,666 \mathrm{P}<0.001\right)$, it was $82.8 \pm 2.16$ days in I. inquinata, $37.9 \pm 0.31$ days in $C$. cephalonica, and $22.3 \pm 0.25$ days in $P$. interpunctella.

As shown in Table 1, the number of $P$. interpunctella adults was never influenced by the presence of $C$. cephalonica. On the contrary, when $P$. interpunctella eggs were started seven days before, the number of $C$. cephalonica that developed into adults decreased. Both species developed in a significantly shorter time when reared alone.

In the experiments with $I$. inquinata, the number of $P$. interpunctella adults was not significantly different (Tab. 2), only the development into an adult took longer. When the two species were started at the same time, no I. inquinata adults were observed. The number of adults and the development period of this species were negatively influenced by the presence of $P$. interpunctella, as the number of emerged adults was significantly lower and the development time was significantly higher.

C. cephalonica was not influenced by the presence of $I$. inquinata as regards the number of emerged adults, while the days required to develop into adults significantly increased (Tab. 3). In the presence of C. cephalonica, the number of $I$. inquinata adults decreased and the development days increased. However, the development days of I. inquinata significantly increased and decreased when $C$. cephalonica eggs were added 7 days before and after, respectively.

Table 1 - Number of emerged adults $( \pm$ S.E.) and development days ( \pm S.E.) of Plodia interpunctella (Hübner) (P.i.) reared alone, with Corcyra cephalonica (Stainton) (C.c.), and with the other species added 7 days after or before the experiment started.

\begin{tabular}{lcccc}
\hline \hline \multirow{2}{*}{ Experiment } & \multicolumn{2}{c}{ Plodia interpunctella } & \multicolumn{2}{c}{ Corcyra cephalonica } \\
\cline { 2 - 5 } & Adults $( \pm$ S.E. $)$ & Development $( \pm$ S.E. $)$ & Adults $( \pm$ S.E. $)$ & Development $( \pm$ S.E. $)$ \\
\hline One species & $18.8 \pm 0.58$ & $22.3 \pm 0.25 \mathrm{c}$ & $17.4 \pm 0.75 \mathrm{a}$ & $37.9 \pm 0.31 \mathrm{c}$ \\
\hline P.i. + C.c. & $17.8 \pm 1.02$ & $27.9 \pm 0.17 \mathrm{~b}$ & $18.6 \pm 0.98 \mathrm{a}$ & $40.6 \pm 0.22 \mathrm{~b}$ \\
\hline P.i. + after 7 dd C.c. & $19.8 \pm 0.20$ & $30.3 \pm 0.49 \mathrm{a}$ & $12.2 \pm 1.88 \mathrm{~b}$ & $56.5 \pm 2.69 \mathrm{a}$ \\
\hline C.c. + after 7 dd P.i. & $16.4 \pm 2.71$ & $30.2 \pm 0.43 \mathrm{a}$ & $20.0 \pm 0.00 \mathrm{a}$ & $40.0 \pm 0.39 \mathrm{~b}$ \\
\hline
\end{tabular}

One-way ANOVA: Plodia interpunctella adults $\mathrm{F}_{3,16}=0.960 \mathrm{P}=0.436$; Development time $\chi^{2}=197.331 \mathrm{P}<0.001$. Corcyra cephalonica adults $\mathrm{F}_{3,16}=54.733 \mathrm{P}<0.001$; Development time $\chi^{2}=87.282 \mathrm{P}<0.001$. Values followed by different letters are significantly different (LSD test and Kruskal-Wallis test).

Table 2 - Number of emerged adults ( \pm S.E.) and development days ( \pm S.E.) of Plodia interpunctella (Hübner) (P.i.) reared alone, with Idaea inquinata (Scopoli) (I.i.), and with the other species added 7 days after or before the experiment started.

\begin{tabular}{lcccc}
\hline \hline \multirow{2}{*}{ Experiment } & \multicolumn{2}{c}{ Plodia interpunctella } & \multicolumn{2}{c}{ Corcyra cephalonica } \\
\cline { 2 - 5 } & Adults $( \pm$ S.E. $)$ & Development $( \pm$ S.E. $)$ & Adults $( \pm$ S.E. $)$ & Development $( \pm$ S.E. $)$ \\
\hline One species & $18.8 \pm 0.58$ & $22.3 \pm 0.25 \mathrm{c}$ & $17.4 \pm 0.75 \mathrm{a}$ & $37.9 \pm 0.31 \mathrm{c}$ \\
\hline P.i. + C.c. & $17.8 \pm 1.02$ & $27.9 \pm 0.17 \mathrm{~b}$ & $18.6 \pm 0.98 \mathrm{a}$ & $40.6 \pm 0.22 \mathrm{~b}$ \\
\hline P.i. + after 7 dd C.c. & $19.8 \pm 0.20$ & $30.3 \pm 0.49 \mathrm{a}$ & $12.2 \pm 1.88 \mathrm{~b}$ & $56.5 \pm 2.69 \mathrm{a}$ \\
\hline C.c. + after 7 dd P.i. & $16.4 \pm 2.71$ & $30.2 \pm 0.43 \mathrm{a}$ & $20.0 \pm 0.00 \mathrm{a}$ & $40.0 \pm 0.39 \mathrm{~b}$ \\
\hline
\end{tabular}

One-way ANOVA: Plodia interpunctella adults $\mathrm{F}_{3,16}=0.960 \mathrm{P}=0.436$; Development time $\chi^{2}=197.331 \mathrm{P}<0.001$ Corcyra cephalonica adults $\mathrm{F}_{3,16}=54.733 \mathrm{P}<0.001$; Development time $\chi^{2}=87.282 \mathrm{P}<0.001$. Values followed by different letters are significantly different (LSD test and Kruskal-Wallis test). 
Table 3 - Number of emerged adults $( \pm$ S.E.) and development days $( \pm$ S.E.) of Corcyra cephalonica (Stainton) (C.c.) reared alone, with Idaea inquinata (Scopoli) (I.i.), and with the other species added 7 days after or before the experiment started.

\begin{tabular}{lcccr}
\hline \hline \multirow{2}{*}{ Test } & \multicolumn{2}{c}{ Corcyra cephalonica } & \multicolumn{2}{c}{ Idaea inquinata } \\
\cline { 2 - 5 } & Adults $( \pm$ S.E. $)$ & Development $( \pm$ S.E. $)$ & Adults $( \pm$ S.E. $)$ & Development $( \pm$ S.E. $)$ \\
\hline One species & $17.4 \pm 0.75$ & $37.9 \pm 0.31 \mathrm{c}$ & $16.2 \pm 1.28 \mathrm{a}$ & $82.8 \pm 2.16 \mathrm{c}$ \\
\hline C.c. + I.i. & $16.4 \pm 0.87$ & $49.4 \pm 0.35 \mathrm{~b}$ & $9.2 \pm 2.27 \mathrm{~b}$ & $124.3 \pm 4.38 \mathrm{a}$ \\
\hline C.c. + after 7 dd I.i. & $15.0 \pm 0.89$ & $51.6 \pm 0.84 \mathrm{a}$ & $4.8 \pm 2.22 \mathrm{bc}$ & $99.8 \pm 4.25 \mathrm{~b}$ \\
\hline I.i.+ after7 dd C.c. & $15.6 \pm 0.98$ & $48.9 \pm 0.49 \mathrm{~b}$ & $2.8 \pm 0.49 \mathrm{c}$ & $69.1 \pm 1.50 \mathrm{~d}$ \\
\hline
\end{tabular}

One-way ANOVA: Corcyra cephalonica adults $\mathrm{F}_{3,16}=1.403 \mathrm{P}=0.278$; Development time $\chi^{2}=182.664 \mathrm{P}<0.001$. Idaea inquinata adults $\mathrm{F}_{3,16}=176.183 \mathrm{P}<0.001$; Development time $\chi^{2}=74.447 \mathrm{P}<0.001$. Values followed by different letters are significantly different (LSD test and Kruskal-Wallis test).

\section{CONCLUSIONS}

Among the species considered in this study, Plodia interpunctella was the most competitive. In fact, the number of individuals of this species that became adults was not influenced by the presence of Corcyra cephalonica or Idaea inquinata. Only a delay in the development was observed when $P$. interpunctella eggs were added to the medium already colonized by the other species. Also in this case, however, the development required fewer days than for the other two species. The short life cycle could be an explanation for the competitiveness of this species, as observed in soybeans in Hemiptera Heteroptera Euschistus heros (F.), that presents a higher number of generations per year and was more competitive than Piezodorus guildinii (Westwood) (TUEHLER et al., 2016).

C. cephalonica was not influenced by the presence of $P$. interpunctella, whether the eggs of the other species were started at the same time or added seven days after. However, the number of $C$. cephalonica adults decreased and the days required to complete the development increased if the eggs of $P$. interpunctella were put in the rearing medium seven days before. In this case, the lower number of $C$. cephalonica adults can be explained by $P$. interpunctella larvae that cannibalize eggs (WHITE \& HUFFAKER, 1969, in Allotey \& Goswami, 1992). In another study, it was observed that larvae of $T$. castaneum (Coleoptera) cannibalized eggs of $C$. cephalonica (NAGALAKSHMI \& BALAJI, 1999). The number of $C$. cephalonica adults was not affected by I. inquinata. In this case, C. cephalonica was the most competitive species, as was observed also in experiments with Cadra cautella (AlloteY, 1986).

I. inquinata is the least competitive species, as it was affected by the presence of both $C$. cephalonica and $P$. interpunctella. In fact, the number of adults decreased and the number of days to adult emergence increased. Actually, I. inquinata development was prevented when eggs of $P$. interpunctella were started contemporaneously. In this case, it was observed that larvae of $P$. interpunctella cannibalized eggs of I. inquinata, even if the food was abundant.

I. inquinata development is slow and this characteristic makes it less competitive (Allotey, 1986). Usually, a higher number of generations per year is considered a favored biology (TUEHLER et al., 2016). Krijger et al. (2001) observed in Drosophila "species with a longer development time suffer more from interspecific competition".

I. inquinata is less competitive compared to the other pest species also due to the adults' lower mobility (Authors' observation). In addition, $C$. cephalonica and P. inter- punctella larvae weave a silk thread that incorporates food and makes food accession for I. inquinata larvae more difficult.

\section{ACKNOWLEDGMENTS}

We would like to thank Dr. Lesley Currah for editing the manuscript, and the anonymous reviewers for their suggestions that improved the manuscript.

\section{REFERENCES}

Allotey J., 1986 - Competition between the two moth Corcyra cephalonica (Stain.) and Ephestia cautella (Wlk.) on laboratory diet. - J. Stored Prod. Res., 22 (3): 103-107.

Allotey J., Kumar R., 1985 - Competition between Corcyra cephalonica (Stainton) and Ephestia cautella (Walker) in cocoa beans. - Insect Sci. Appl., 6 (5): 627. 632.

Allotey J., Goswami L., 1992 - Competition between the phycitid moths Plodia interpunctella (Hubn) and Ephestia cautella (Wlk) in groundnuts and on a laboratory diet. Insect Sci. Appl., 13 (5): 719-723.

Arbogast R.T., 2007 - A wild strain of Plodia interpunctella (Hübner) (Lepidoptera: Pyralidae) from farm-stored maize in South Carolina: development under different temperature, moisture, and dietary conditions. J. Stored Prod. Res., 43 (2): 160-166.

CANDURa G.S., 1931a - Studio sulla Tignola del fieno (Ptychopoda herbariata). - Bollettino di Zoologia Generale e agraria di Portici, 24: 233-266.

CANDURA G.S., 1931b - Ricerche sugli insetti e sui danni da essi causati ai prodotti dell'economia rurale o delle industrie agrarie. $2^{\circ}$ Contributo - Gli insetti della camomilla secca e di altre erbe medicinali e industriali disseccate. - Bollettino della Società Naturalistica di Napoli, 43: 343-350.

Cox P.D., Crawford L.A., Gjestrud G., Bell C.H., BOWLEY C.R., 1981 - The influence of temperature and humidity on the life-cycle of Corcyra cephalonica (Stainton) (Lepidoptera, Pyralidae). - Bull. Entomol. Res., 71 (2): 171-181.

Cui J., Deng Y., Wang J., YAng L., Yang Z., JAng T., 2006 - Effects of interspecific competition on the population dynamics of four stored grain insect pests. - Zool. Res., 27 (3): 275-280.

Devescovi F., Liendo M.C., Bachmann G.E., Bouvet J.P., Milla F.H., Vera M.T., Cladera J.L., Segura D.F., 
2015 - Fruit infestation patterns by Anastrepha fraterculus and Ceratitis capitata reveal that crossrecognition does not lead to complete avoidance of interspecific competition in nature. - Agr. Forest Entomol., 17: 325-335.

Dudley T.L., D'antonio C.M., Cooper S.D., 1990 Mechanisms and consequences of interspecific competition between two stream insects. - J. Anim. Ecol., 59: 849-866.

Eatough Jones M., Hanlon C.C., Paine T.D., 2015 Potential for interspecific competition between congeneric longhorned beetle species (Coleoptera: Cerambycidae) in an adventive environment. - Environ. Entomol., 44: 960-965.

Fabre J.P., Auger-Rozenberg M.A., Chalon A., Boivin S., Roques A., 2004 - Competition between exotic and native insects for seed resources in trees of a Mediterranean forest ecosystem. - Biol. Invasions, 6: 1122.

Flamigni C., Bastia G., 1998 - Osservazioni sulle specie emiliane del genere Idaea Treitschke, 1825 (Insecta Lepidoptera Geometridae). - Quaderno di Studi e Notizie di Storia Naturale della Romagna, 9: 13-42.

Gianti M., 2001 - Sulla presenza in Piemonte di alcune specie del genere Idaea Treitschke, 1825 (Lepidoptera Geometridae). - Bollettino del Museo Regionale di Scienze Naturali di Torino, 18 (2): 409-412.

Giga D.P., Canhao S.R., 1993 - Competition between Prostephanus truncatus (Horn) and Sitophilus zeamais (Motsch.) in maize at two temperatures. - J. Stored Prod. Res., 29 (1): 63-70.

Johnson J.A., Wofford P.L., Gill R.F., 1995 Development thresholds and degree-day accumulations of Indianmeal moth (Lepidoptera: Pyralidae) on dried fruits and nuts. - J. Econ. Entomol., 88: 734-742.

KAPLAN I., DENNO R.F., 2007 - Interspecific interactions in phytophagous insects revisited: a quantitative assessment of competition theory. - Ecol. Lett., 10: 977-994.

KARBAN R., 1986 - Interspecific competition between folivorous insects on Erigeron glaucus. - Ecology, 67(4): 1063-1072.

KratochVil J., 1948 - Màlo znàmý škudce paprika, zeleniny e lèciých bylin. - Ochrana rostlin, 19-20: 49-54.

Krijger C.L., Peters Y.C. Sevenster J.G., 2001 Competitive ability of neotropical Drosophila predicted from larval development times. - Oikos, 92: 325-332.

Limonta L., Locatelli D.P., 2013 - Study of the postembryonic development of Idaea inquinata under different abiotic factors. - Bull. Insectol., 66 (1): 21-25.

Locatelli D.P., Di Egidio V., Stampini M., 2005 Observations of the development of Idaea inquinata (Scop.) (Lepidoptera Geometridae) on medicinal plants and other food substrates. - Boll. Zool. Agr. e Bachic., Serie II, 37 (2): 123-132.
NAGALAKSHMI V.K., BALAJI S., 1999 - Effect of common red flour beetle Tribolium castaneum (Herbst) (Tenebronidae: Coleoptera) on the life cycle of the rice moth Corcyra cephalonica (Stainton) (Galleriidae: Lepidoptera). - Proceeding of the XXIII ISSCT Congress, New Delhi, India, 22-26 February, 1999. n. 2. Sugar Technologists'Association of India, pp. 578-585.

NAVES C.H., 1995 - Idaea inquinata recently found in the Netherlands (Lepidoptera: Geometridae). - Entomologische berichten, Amsterdam, 55 (12): 195-196.

Ntiri E.S., Calatayud P.A., Van Den Berg J., Schulthess F., LE RU B.P., 2016 - Influence of temperature on intraand interspecific resource utilization within a community of lepidopteran maize stemborers. - PlosOne, 11 (2): $\mathrm{e} 0148735$.

Olsson P.O.C., Anderbrant O., Löfsted C., 2006 Experience influences oviposition behaviour in two pyralid moths, Ephestia cautella and Plodia interpunctella. - Anim. Behav., 72: 545-551.

Sakka M.K., Athanassiou C.G., 2018 - Competition of three stored-product bostrychids on different temperatures and commodities. - J. Stored Prod. Res., 79: 34-39.

SAvov D., 1973 - Development of Plodia interpunctella $H b$. (Lepidoptera: Pyralidae) in the optimum temperature range. - Grad. Loz. Nauka, 10 (5): 33-40.

Schoonhoven L.M., VAN LoON J.J., Dicke M., 2005 Insect-plant biology. Second ed: Oxford University Press, pp. 421.

SIGMON E., 2015 - Interspecific variation in aggressive fighting behavior of shelter-building caterpillars. - J. Insect Behav., 28: 403-416.

Sмith R.M., 1986 - Oviposition, competition and population dynamics in storage insects. Proceedings, 4th International Working Conference on Stored-Product Protection, September 21-26, 1986, Tel Aviv, pp. 426433.

SKINNER B., 1984 - Moths of the British Isles. - Viking, Penguin Books, Harmondsworth, pp. 1-267.

TEMPEL W., 1941 - Beiträge zur kenntnis der Lebenweise und der Bekämpfung des Heuspanners (Acidalia herbariata $F$.). - Arbeiten über physiologische und angewandte Entomologie aus Berlin-Dahlem, 8: 128-138.

Tuelher E., Éder S., Silva H., Hirose E., Narciso R., Guedesa C., Oliveira E., 2016 - Competition between the phytophagous stink bugs Euschistus heros and Piezodorus guildinii in soybeans. - Pest Manag. Sci., 72: 1837-1843.

White E.G., HufFaKer C.D., 1969 - Regulatory processes and population cyclicity in laboratory populations of Anagasta kuhniella (Zeller) (Lepidoptera: Phycitidae) I. Competition for food and production. - Researches Popul. Ecol. Kyoto Univ., II: 57-83. 